\title{
RESEARCHING THE POSSIBILITY OF FORMATION OF THE ION ASSOCIATES OF FOOD AZO DYE CARMOISINE (E122) WITH ORGANIC AMINES
}

\author{
Anna Materiienko', Vladimir Grudko ${ }^{1}$, Victoria Georgiyants ${ }^{1}$, Vadim Khanin ${ }^{2}$ \\ ${ }^{1}$ National University of Pharmacy, Kharkiv, Ukraine \\ 2"Zdorovye" Pharmaceutical company, Kharkiv, Ukraine
}

\begin{abstract}
PURPOSE: Carmoisine is the synthetic food dye used in the manufacture of some medicals and food products. Previously, we had already established, that it is able to form the ion associates with chlorpheniramine maleate and in this way can be extracted from water solution with chloroform. The aim of the work is establishment of partition coefficients of the associate for water and different organic solvents, and research the interaction of the carmoisine with certain organic amines.

MATERIAL AND METHODS: As the object of research the synthetic food dye carmoisine was selected. Analytical studies were performed by the method of UV and visible spectrophotometry.

RESULTS AND CONCLUSIONS: As the result of the work performed, the partition coefficients of the associate of carmoisine and chlorpheniramine maleate for various systems water-organic solvent were spectrophotometrically established and it was shown, that the associate is better soluble in cyclohexanol, 2-octanol, and butanol. The formation of ion associates between carmoisine and some organic amines was established experimentally. The partition coefficients for the obtained ion associates were calculated. It was shown, that the associate of carmoisine with myramistine has the highest partition coefficient.
\end{abstract}

Keywords: carmoisine, ion associates, extraction, spectrophotometry, organic amines

\section{INTRODUCTION}

Recently, due to the rapid growth of the desire to make commercially attractive products in the food and pharmaceutical industries, the human body accumulates more and more synthetic molecules, whose interaction between each other has been insufficiently studied. For example, in the com-

Address for correspondence:

Anna Materiienko

National University of Pharmacy,

53 Pushkinska str.

61002 Kharkiv, Ukraine,

e-mail:anna.materienko@gmail.com

Received: April 8, 2015

Accepted: December 1, 2015 position of food and medicines to the organism arrive excipients such as dyes, among which today synthetic azo dyes are dominant (1). This group includes carmoisine:

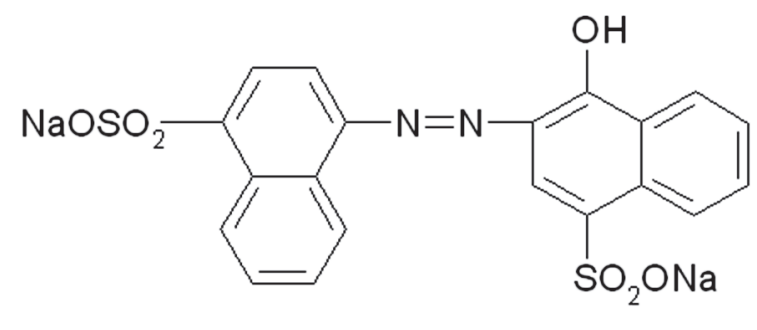

carmoisine

Carmoisine (4-hydroxy-3-(4-sulfonate1-naftilazo)-1-naphthalene sulfonate, disodium salt 
Anna Materiienko, Vladimir Grudko, Victoria Georgiyants et al.

is a red coloured dye, with a melting point above $300^{\circ} \mathrm{C}$, obtained by azo coupling reaction of diazotized 4-sulfonate-1-naphthylamine with 4-sulfonate1-naphthol, is highly soluble in water, ethanol, and is insoluble in chloroform $(2,3)$.

We have found that this dye is capable of reacting with lidocaine hydrochloride and chlorpheniramine maleate to form ion associates, which are soluble in chloroform and peach oil $(4,5)$. Previously, we have studied the properties of the ion associate of carmoisine with chlorpheniramine maleate: the dependence of extraction from the $\mathrm{pH}$ of water solution, the stoichiometric ratio of the components in the ion associate and a partition coefficient in a water-chloroform system $(4,6)$.

Further study of the properties of this ion associate, as well as exploring the possible formation of carmoisine associates with a variety of primary, secondary, tertiary amines and salts of quaternary ammonium compounds is highly relevant, since obtained data will be used for further development of control methods of fullness cleaning equipment process after using dyes in the manufacturing.

\section{MATERIAL AND METHODS}

For the experimental research we used: $1 \times 10^{-3}$ $\mathrm{M}$ aqueous solutions of carmoisine, pyridine, morpholine, triethylamine, chlorpheniramine maleate, myramistine and ethacridine lactate, $1 \times 10^{-3} \mathrm{M}$ tribromaniline alcoholic solution and $2 \times 10^{-3} \mathrm{M}$ alcoholic solution of diphenylamine. We used phosphate buffer solutions to create a specific $\mathrm{pH}$.

The analytical equipment was Evolution 60S (USA) spectrophotometer; AXIS ANG200 balances (Poland); pH-150 MI potentiometer (Ukraine). For the operation we used measuring glassware of class $A$ and excipients meeting the requirements of the State Pharmacopoeia of Ukraine (SPhU) (7) which are harmonized with the European ones (8).

The establishment of the partition coefficients for different solvents

Method of implementation: $5.0 \mathrm{ml}$ of $1 \times 10^{-3} \mathrm{M}$ chlorpheniramine maleate solution, $0.5 \mathrm{ml}$ of $1 \times 10^{-3}$ $\mathrm{M}$ carmoisine solution, $45.0 \mathrm{ml}$ of water $\mathrm{R}$ were placed into a separating funnel and mixed for 2 minutes. Stock solution was measured spectrophotometrically at a wavelength of 450-550 $\mathrm{nm}$ against water $\mathrm{R}(3,8)$. The formed ion associate was extracted once with an organic solvent, a portion of $25.0 \mathrm{ml}$. The aqueous layer after extraction was also measured in a spectrophotometer over the wavelength range 450-550 nm against a blank solution $(7,8)$. The necessity of measuring the spectrum in this range is explained by the possibility of maximum displacement due to the effect of an organic amine on the properties of the formed associate. We found the values of absorption at the maximum and calculated the concentration of carmoisine in the initial solution and the aqueous solution after extraction by the standard method. The concentration of carmoisine in the extraction was found by the difference of the concentrations of the initial solution and the aqueous solution after extraction. The partition coefficient was calculated by the formula:

$$
K=\frac{C_{2}}{C_{1}},
$$

where:

$\mathrm{C}_{1}$ - is the carmoisine concentration in the initial water solution;

$\mathrm{C}_{2}$ - is the carmoisine concentration in the obtained extract solution.

The results are given in the Table 1.

Studying the possibility of forming the ion associates of carmoisine with some amines

Method of implementation: into a separating funnel the exact amount of the organic amine solution was placed, $0.5 \mathrm{ml}$ of $1 \times 10^{-3} \mathrm{M}$ carmoisine solution and $45.0 \mathrm{ml}$ of water $\mathrm{R}$ or phosphate buffer solutions was added. The solution was mixed for $2 \mathrm{~min}$ utes and stock solution was measured spectrophotometrically at a wavelength of 450-550 nm against a blank solution $(7,8)$. The formed ion associate was extracted once with an organic solvent, a portion of $25.0 \mathrm{ml}$. The aqueous layer after extraction was also measured in a spectrophotometer over the wavelength range 450-550 $\mathrm{nm}$ against a blank solution. We found the values of the absorption at the maximum and calculated the concentration of carmoisine in the initial solution and the aqueous solution after extraction by the standard method $(7,8)$. The concentration of carmoisine in the extraction was found by the difference between the concentrations of the initial solution and the aqueous solution after extrac- 
tion. The partition coefficient was calculated by the formula (1.1). The results are given in Table 2.

\section{RESULTS AND DISCUSSION}

The research results make it possible to assert that the highest partition coefficients for the associate of carmoisine with chlorpheniramine maleate are observed for cyclohexanol, 2-octanol, and butanol (Table 1).

Table 1. The partition coefficients for the associate of
carmoisine with chlorpheniramine maleate for some
solvents
\begin{tabular}{|ccc} 
№ & C2/C1 & Solvent \\
1 & $\mathbf{8 . 6 2}$ & Butanol \\
2 & 2.03 & 2-methylpropanol-1 \\
3 & 2.14 & 2-methylpropanol-2 \\
4 & 2.70 & benzyl alcohol \\
5 & 2.50 & amyl alcohol \\
6 & 2.81 & 2-methylbutanol-4 \\
7 & 0.48 & 1-octanol \\
8 & $\mathbf{1 6 . 9 2}$ & 2-octanol \\
9 & $\mathbf{2 8 . 0 0}$ & Cyclohexanol \\
\hline \hline
\end{tabular}

The analysis of calculated partition coefficients for obtained ion associates of carmoisine with different organic amines indicates that: the ion associates of carmoisine with diphenylamine, tribromaniline, pyridine, triethylamine and morpholine are practically insoluble in chloroform, they are more fully extracted from the aqueous solution with a $\mathrm{pH}$ of 6.2 by butanol with a molar ratio of components (carmoisine:organic amine) 1:1 (Table 2).

The ion associate of carmoisine with ethacridine lactate is not extracted by chloroform, is practically insoluble in ethyl acetate and was most fully extracted from the aqueous solution by butanol without adding the buffer solution. The associate of carmoisine with myramistine with a molar ratio of components (carmoisine:myramistine) 2:1 is the most soluble in chloroform (Table 2). The highest partition coefficient for the associate of carmoisine with myramistine in the chloroform-water system was observed for water solution without adding the buffer solution.
These results suggest that when developing control methods of cleaning equipment after using it in manufacturing of food dyes (in particular, carmoisine) can be used in reaction with myramistine and subsequent extraction of the associate with chloroform from the wash water.

\section{CONCLUSIONS}

1. Formation of ion associates between carmoisine and various organic amines (including medicinal substances - chlorpheniramine maleate and myramistin), soluble in butanol, chloroform, ethyl acetate and fatty oils were proved experimentally.

2. The highest partition coefficients for ion associate of carmoisine with chlorpheniramine maleate occur in cyclohexanol-water, 2-octanol-water, butanol-water systems.

3. The partition coefficients of the obtained ion associates for various organic solvents were calculated. The associate of carmoisine with myramistin has the highest partition coefficient.

4. The obtained results can be used in the development of control methods for complete cleaning equipment processes after using them in manufacturing of some food azo dyes (in particular, carmoisine).

\section{REFERENCES}

1. Ash M. Handbook of Pharmaceutical Additives, $3^{\text {rd }}$ ed. NY: Synapse Information Resources, Inc; 2007.

2. Combined compendium of food additive specifications. JECFA. Vol.4 Analytical methods, test procedures and laboratory solutions used by and referenced in the additive specification. Rome: FAO; 2006.

3. Lastuhin YO. Food Additives. E-codes. Structure. Obtaining. Properties. Teach. guide. Lviv: Centre of Europe; 2009. p 836.

4. AS Materienko, VA Grudko, VA Georgianc. A study of ion associates of food azo dye carmoisine (E122) with medicinal substances. Vestnik KazNMU. Scientific-practical journal of medicine. 2013;5(3):27-31.

5. AS Materiienko, VA Hrudko, VA Georgiyants. Methodology development definitions of tartrazine and carmoisine in the syrup «Gripout baby»". 
Anna Materiienko, Vladimir Grudko, Victoria Georgiyants et al.

Table 2. The partition coefficients for the associate of carmoisine with different organic amines

\begin{tabular}{|c|c|c|c|c|c|c|}
\hline \multirow{2}{*}{ No. } & \multirow{2}{*}{ Reagent } & \multirow{2}{*}{$\mathrm{pH}$} & \multirow{2}{*}{$\begin{array}{l}\text { Volume of } \\
\text { reagent }\end{array}$} & Butanol & Chloroform & Ethyl acetate \\
\hline & & & & $\mathrm{C}_{2} / \mathrm{C}_{1}$ & $\mathrm{C}_{2} / \mathrm{C}_{1}$ & $\mathrm{C}_{2} / \mathrm{C}_{1}$ \\
\hline 1 & & 4.2 & 2.5 & 1.38 & 0.10 & 0.19 \\
\hline 2 & diphenylamine & 6.2 & 2.5 & 4.08 & 0.03 & 0.38 \\
\hline 3 & & - & 2.5 & 0.07 & 0.03 & 0.46 \\
\hline 4 & & 4.2 & 5.0 & 1.90 & 0.22 & 0.24 \\
\hline 5 & tribromaniline & 6.2 & 5.0 & 4.02 & 0.06 & 0.39 \\
\hline 6 & & - & 5.0 & 0.21 & 0.17 & 0.57 \\
\hline 7 & & 4.2 & 5.0 & 1.55 & 0.12 & 0.15 \\
\hline 8 & pyridine & 6.2 & 5.0 & 4.15 & 0.06 & 0.10 \\
\hline 9 & & - & 5.0 & 0.26 & 0.03 & 0.46 \\
\hline 10 & & 4.2 & 5.0 & 1.62 & 0.11 & 0.32 \\
\hline 11 & triethylamine & 6.2 & 5.0 & 4.10 & 0.05 & 0.22 \\
\hline 12 & & - & 5.0 & 0.67 & 0.14 & 0.37 \\
\hline 13 & & 4.2 & 5.0 & 3.25 & 0.07 & 0.19 \\
\hline 14 & morpholine & 6.2 & 5.0 & 3.53 & 0.02 & 0.17 \\
\hline 15 & & - & 5.0 & 0.53 & 0.07 & 0.20 \\
\hline 16 & & 4.2 & 5.0 & 1.27 & - & 0.37 \\
\hline 17 & ethacridine lactate & 6.2 & 5.0 & 1.61 & - & 0.07 \\
\hline 18 & & - & 5.0 & 5.38 & - & 0.20 \\
\hline 22 & & 4.2 & $0.5\left(0.25^{\star}\right)$ & 2.41 & 1.39 & 0.59 \\
\hline 23 & myramistine & 6.2 & $0.5\left(0.25^{\star}\right)$ & 2.34 & 1.49 & 0.37 \\
\hline 24 & & - & $0.5\left(0.25^{\star}\right)$ & 2.71 & 1.82 & 0.48 \\
\hline
\end{tabular}

* extracting with chloroform

Belgorod State University. Scientific bulletin. Medicine. Pharmacy. 2013;25 (168). Issue 24: p 232-238.

6. AS Materiienko, VO Grudko, VA Khanin, VA Georgiyants. Determination of the food azo dye carmoisine vs chlorpheniramine maleate ion associate structure. News of Pharmacy. 2014; 3(79): p 34-37.

7. State Pharmacopoeia of Ukraine. SOE "Scientific-and-expert Pharmacopeial Centre". 1st ed.
Kharkiv: SOE "Scientific-and-expert Pharmacopeial Centre”; 2001. Ukrainian.

8. European Pharmacopoeia. Available from: http:// online6.edqm.eu/ep802/ 